\title{
O Brasil e a dimensão econômico-social do governo Lula: resultados e perspectivas
}

\author{
Carlos Eduardo Martins \\ Universidade Estácio de Sá
}

O Brasil e a dimensão econômico-social do governo Lula: resultados e perspectivas

Resumo: Este artigo avalia a trajetória da economia brasileira desde os anos 1980 e as dimensões que alcança com o governo Lula. Assinala as estruturas de poder internas que se criaram neste período e que deslocaram o eixo da acumulação para o setor financeiro. Aponta que a hegemonia financeira entra em contradição com a nova fase de expansão do capitalismo mundial iniciada em 1994, o que leva ao contraste entre as taxas de crescimento brasileiras - muito baixas - e as da economia mundial que estão em aceleração. Aponta finalmente que um dos desafios do governo Lula para atender às expectativas sociais que se criaram sobre ele, é o romper com esta hegemonia para impulsionar o desenvolvimento e a inclusão.

Palavras-chave: governo Lula, economia brasileira, políticas sociais, desenvolvimento.

Brazil and the Social Economic Dimension of the Lula Government: Results and Perspectives

Abstract: The article evaluates the trajectory of the Brazilian economy since the 1980's and the dimensions that it has reached under the Lula government. It indicates the internal power structures that were created in this period and that shift the axis of accumulation to the financial sector. It indicates that the financial hegemony contradicts the new phase of expansion of global capitalism begun in 1994, which led to a contrast between Brazil's very low growth rates - and accelerating growth of the world economy. It finally indicates that one of the challenges of the Lula government to meet the social expectations that it had created, is to break with this hegemony in order to stimulate development and inclusion.

Key words: Lula government, Brazilian economy, social policies, development. 


\section{Introdução}

Desde meados dos anos 1990, a economia mundial ingressou num ciclo de crescimento econômico de longo prazo. Este ciclo se manifesta, entre outros aspectos, na substancial elevação das taxas de crescimento econômico do PIB e do PIB per capita, na centralidade que passa ter a taxa de lucro nos investimentos e na contenção das taxas de juros e da dívida pública. Entretanto, o Brasil vem participando muito precariamente deste novo ciclo de desenvolvimento da economia mundial. O setor financeiro exerce protagonismo nas políticas públicas do país, restringindo as perspectivas de crescimento econômico, sua sustentabilidade e o alcance de uma política externa de afirmação regional e de diversificação das relações comerciais e das parcerias internacionais.

Esse protagonismo do setor financeiro se inicia na história recente do país na década de 1980. Ele é prolongado nas décadas seguintes através de diferentes padrões de políticas públicas, nos governos Fernando Henrique Cardoso (1994-2002) e no primeiro mandato de Lula (2003-2006), que priorizam o controle da inflação, a ser combatida através da contenção da demanda agregada, e a abertura comercial e financeira. Se há continuidades entre estas gestões convém, entretanto, ressaltar suas diferenças. A gestão de Fernando Henrique Cardoso (FHC) pode ser inserida dentro de um padrão tipicamente neoliberal de políticas públicas: crescimento da dívida externa, expansão acelerada da dívida pública, expressivos déficits em conta corrente, elevadas taxas de juros, privatização, desmonte dos segmentos de maior valor agregado de nossas indústrias, desregulamentação do mercado de trabalho e abertura comercial e financeira acelerada através de políticas de valorização cambial, posteriormente revertida ao câmbio flutuante, o que implicou a multiplicação das dívidas em dólar no PIB nacional. O governo Lula, por sua vez, enquadra-se mais tipicamente em um padrão de governo de terceira via. Volta-se para a contenção dos desequilíbrios macroeconômicos gerados no governo anterior e busca substituir a agenda de políticas públicas, mas condiciona o alcance de sua implementação à liberação de excedentes econômicos a serem alcançados através de uma gestão que preserve os contratos e os mecanismos de mercado, particularmente os do setor financeiro. No centro da ação governamental está a construção de um ajuste na economia que neutralize a expansão dos desequilíbrios anteriores, vistos como geradores de inflação, e os reverta. Assim, torna-se fundamental a geração de amplos superávits comerciais e fiscais que limitem a demanda agregada e contenham a espiral do endividamento externo e interno. As políticas sociais, o combate à pobreza, a recuperação do setor industrial e do desenvolvimento, ou o ativismo da política externa tornam-se objetivos condicionados às metas de estabilidade macroeconômica.

Esta tensão entre as agendas social, externa e de recuperação do desenvolvimento, de um lado, e o enfoque ortodoxo sobre a inflação, de outro, que destina os superávits fiscais e comerciais para financiar os juros e serviços do endividamento, constitui uma importante dimensão do governo Lula. Entretanto, cumpre ressaltar a contradição entre esta gestão que limita o crescimento econômico e o ambiente internacional que o estimula. Isto está na base das medíocres taxas de crescimento exibidas pelo Brasil em relação ao desempenho da economia mundial, sobretudo desde 1994, quando o diferencial de crescimento ampliase ou, mais recentemente, em relação à própria América Latina. Longe de ser adequada às tendências mais dinâmicas do capitalismo mundial, estas políticas atendem, sobretudo, às determinações internas de poder controladas pela grande burguesia e as elites locais.

\section{Desempenho da economia mundial versus de- sempenho brasileiro}

Desde 1994, a economia mundial retomou seu crescimento acelerado, expandindo-se, entre 19942005, em 2,3\% a.a. per capita, nível bastante superior ao período 1974-93, quando sua expansão foi de 1,2\% (MADDISON 2001; U.S. GOVERNMENT, 2006). Postulamos que este desempenho está relacionado ao fato de a economia mundial ter ingressado na fase A de um ciclo de Kondratiev de aproximadamente 20 a 25 anos. Neste período está sujeita a pequenas recessões que são etapas de ajuste e transição em sua longa expansão, dividida entre retomada, prosperidade e maturidade. Em 2001-2002, uma curta recessão, quando o crescimento do PIB per capita cai para $1,4 \%$ a.a., marca a transição para a prosperidade, que o eleva novamente a $3,1 \%$ a.a. entre 2003-2005. Incrementam-se no período fortemente os fluxos de capital estrangeiro na economia mundial, expressando esta expansão. Entre 1994-2000, estes se expandem em 27,4\% a.a., saltando de US\$288,5 bilhões, em 1994, 
para US\$ 1.249 bilhões em 2000. Recuam no contexto da crise de 2001-2002, alcançando US\$ 652 bilhões em 2002, mas se elevam a U\$ 896 bilhões em 2005, indicando o curso de uma nova trajetória de expansão (UNCTAD, 2005).

Entretanto, se observarmos o desempenho do Brasil, veremos um resultado em descompasso com este ascenso. Desde 1994, a economia brasileira cresce a $1,3 \%$ a.a. per capita, ritmo próximo à crise econômica de longo prazo da economia mundial. Este ainda se reduz nos anos mais recentes. Assim entre 1994-2002, durante o governo Fernando Henrique Cardoso (FHC), a economia brasileira se expandiu em $1,4 \%$ a.a. per capita e, durante, o governo Lula, voltado para corrigir os desequilíbrios macroeconômicos do governo anterior através do corte da demanda agregada, a expansão per capita anual cai a 1,1\% (BANCO CENTRAL DO BRASIL, 2006) ${ }^{1}$. No que tange a recepção de investimentos diretos estrangeiros, a participação brasileira cai no âmbito da economia mundial e da América Latina. Entre 1995-2000 representava 3\% dos fluxos mundiais de capitais e $35 \%$ dos recebidos pela América Latina e, em 2005 , respectivamente, $1,6 \%$ e $22 \%$ (CEPAL, 2005) ${ }^{2}$.

Quais os determinantes desta marginalização do país da economia mundial e que lhe desloca negativamente o poder econômico na própria América Latina? A resposta exige situar dimensões externas e internas que não atuam de maneira independente, mas inter-relacionadas.

No plano da economia mundial, a mundialização da revolução científico-técnica exige cada vez mais a elevação das qualificações dos trabalhadores para impulsionar a competitividade e a produtividade das empresas. Esta nova etapa expansiva está fortemente fundada no paradigma microeletrônico e suas características sistêmicas que dependem crescentemente do desenvolvimento da subjetividade dos trabalhadores. As zonas que mais atraem investimento na economia mundial são aquelas que articulam maior qualidade do trabalho e menor custo relativo. A superexploração, que estrutura o capitalismo na América Latina, prioriza a competição pelo baixo custo e reduz os gastos com a força de trabalho, o que resulta em ônus crescente para a inserção da região e do Brasil na economia mundial. A importância crescente que vem ganhando o Leste Asiático nos fluxos internacionais de capitais reflete esta realidade ${ }^{3}$. Os países que o compõe, como Japão, Coréia do Sul, Taiwan e China, realizaram importantes reformas sociais - como a reforma agrária -, investiram fortemente em educação e na construção de um poderoso sistema nacional de ciência e tecnologia.

A crise da hegemonia dos Estados Unidos. Esta crise tem duas dimensões. A primeira é que os Estados Unidos, ao invés de injetarem liquidez na economia mundial, como entre os anos 1940 e meados dos anos 1970, tornaram-se um captador de liquidez desta, em função de suas necessidades de cobrir os seus crescentes déficits em conta corrente. Isto tem reduzido fortemente a sua participação nos investimentos diretos mundiais ${ }^{4}$. Se no período da expansão de sua hegemonia, sua maior presença nos investimentos mundiais beneficiava a América Latina, área de sua hegemonia regional, o seu descenso a prejudica, restringindo o volume de investimentos que lhe são direcionados. Entretanto, cumpre destacar ainda outra dimensão da crise. Ao assumir o neoliberalismo como ideologia de resposta à crise, os Estados Unidos não apenas impulsionaram a sobrevalorização do dólar para repatriar e internalizar capitais, mas redefiniram a divisão internacional do trabalho. Esta ao invés de se dirigir a mercados internos, orienta-se cada vez mais para o mercado mundial e descentraliza amplamente os processos produtivos, uma vez que o monopólio se transfere para o domínio do conhecimento. Desta forma, países como o Brasil que tinham em seu mercado interno o diferencial frente a outros países dependentes para a captação de investimento estrangeiro são ameaçados nesta capacidade por uma outra lógica de distribuição de investimentos. Esta busca descentralizar processos produtivos para zonas fronteiriças, aproveitando-se do trabalho superexplorado da periferia, para reduzir custos de mão-de-obra e de transporte e aumentar a competitividade do produto final. Assim, o México e a América Central, tornam-se zona prioritária de recepção de investimentos dos Estados Unidos, o que desloca amplamente os investimentos que seriam direcionados à América do Sul e ao Brasil ${ }^{5}$.

Um terceiro ponto, de grande importância, refere-se às políticas públicas praticadas no Brasil. A financeirização da economia brasileira, que eleva significativamente os juros acima do crescimento econômico, restringe os investimentos e mantém uma situação de risco para as aplicações financeiras, limitando a entrada de capitais estrangeiros no país. Entre 1979-92, os juros foram o grande fator de atração de capitais na economia mundial. Seu grande instrumento, os títulos da divida pública dos Estados Unidos. Entretanto, esta situação muda a partir de 1993. O brutal aumento da dívida pública nos Estados Unidos, aliado às condições que permitiram a elevação das taxas de lucro - como a nova onda de inovações tecnológicas, a redução salarial nos anos 1980 e as novas técnicas de gestão -, levou à redução dos juros e à substituição dos títulos da dívida pública pelas fusões, aquisições, investimento direto e em bolsas de valores como principal fonte de atração e deslocamento de capitais. Para isso os lucros, ainda que auxiliados pela especulação cambial, tornaram-se chave. A acumulação de capitais que se desenvolve a partir de 1994 na economia mundial está sendo dirigida fundamentalmente pelo capital produtivo, ainda que com importantes mediações. Entre 
1994-98, a especulação financeira, associada aos juros, ainda mantém um papel importante, mas subordinado nas estratégias de investimento internacionais. Seus alvos deslocam-se para os países dependentes, onde o Brasil joga um papel de destaque. A partir de 1999, quando se evidenciam as vulnerabilidades sistêmicas dos países que se apóiam na combinação entre juros e câmbio sobrevalorizado, os Estados Unidos reorientam sua estratégia de expansão internacional para acentuar a busca da competitividade de suas mercadorias mediante o barateamento de seus custos de produção e uma maior penetração no setor de serviços ${ }^{6}$. Nesse contexto, a manutenção de altas de juros se torna um forte obstáculo para o Brasil disputar os fluxos internacionais de capital da economia mundial.

Pressionado pela relocalização dos fluxos de capitais da economia mundial para ativos de qualidade no Leste asiático ou para ativos de baixo custo no México e América Central, aproveitando-se dos baixos custos de transporte, o Estado brasileiro não encontrou ainda uma forma de responder a estes desafios da economia mundial, o que vem resultando na perda de poder econômico relativo do país. Para inverter esta tendência o Estado brasileiro tem que superar dois obstáculos: a) seu compromisso com a financeirização; b) a exclusão social, a qual nos converte em receptores de capital que buscam lucros através de ativos de baixa qualidade, como a superexploração do trabalho, que limita novas entradas e nos submete a uma sangria internacional de divisas.

\section{Estado brasileiro: financeirização e evolução re- cente}

A recente financeirização do Estado brasileiro se inicia na década de 1980, no contexto da crise da dívida externa. Para transferir os excedentes econômicos relacionados aos pagamentos de juros e serviços desta dívida, o governo brasileiro impulsionou a dívida interna através da venda de títulos da dívida pública, trocando-os pelos dólares obtidos pelo saldo comercial para remetê-los ao exterior. A incapacidade de conferir liquidez à dívida diante dessas transferências impulsionou as taxas de juros e o peso do setor financeiro na economia brasileira. A participação do setor financeiro na economia brasileira que era de $6 \%$ do PIB em 1970, ampliou-se para 7,8\% do PIB em 1980 e, então, salta para 19,5\% do mesmo em 1989, enquanto a da indústria cai de $33 \%$ do PIB para $22,8 \%$, no período, e a taxa de investimento declina dos $24,6 \%$ do PIB para $18,1 \%$, entre 1980 88. Por outro lado, o peso das dívidas interna e externa no PIB saltou de $32 \%$ a $51,7 \%$ entre $1982-87$, para posteriormente cair no contexto da renegociação da dívida externa através do Plano Brady para 33,1\%, em 1993 (CEPAL, 2005; IPEA, 2006; BANCO CENTRAL DO BRASIL, 2006). Entretanto, ela volta a se elevar durante o governo FHC e o Plano Real.

A negociação brasileira do Plano Brady que se inicia durante o governo Collor (1990-1992) através de Pedro Malan, então consultor especial e negociador-chefe para Assuntos da Dívida Externa do Ministério da Fazenda, estabelece como contrapartida para a redução da dívida externa e de seus juros as aberturas comercial e financeira e a privatização da economia brasileira. A dívida interna volta então a se ampliar por duas razões: a) a necessidade de captar liquidez internacional para cobrir os déficits em conta corrente produzidos pela valorização cambial e a abertura comercial geradas pelo plano real; b) a necessidade de compensar os efeitos negativos da abertura e da sobrevalorização cambial sobre a lucratividade do setor industrial e produtivo, o que aprofunda a financeirização da burguesia brasileira e suas expectativas de auferir rendas elevadas por uma vinculação privilegiada com o Estado através do mercado dos títulos da dívida pública.

A dívida interna salta então de $25 \%$ do PIB em 1995 para 35,5\% do PIB, em 1998, apesar do extenso programa de privatizações conduzido sob a liderança do governo federal, do aumento expressivo da arrecadação orçamentária e da forte ampliação da dívida externa ${ }^{7}$. A ampliação da dívida interna nos anos 1990 vem incorporar, entre um de seus importantes investidores, os fundos de pensão dos trabalhadores de empresas estatais ou ex-estatais. Ao final do governo FHC, em 2002, a dívida interna havia alcançado $41,5 \%$ do PIB e os seus detentores eram eminentemente atores nacionais ${ }^{8}$ : bancos comerciais nacionais, fundos de investimento financeiro, onde têm papel destacado os fundos de pensão. Desenvolve-se um complexo sistema de poder econômico e - com a chegada de Lula à presidência - político, onde um grupo altamente estratificado de trabalhadores integra-se à financeirização da economia brasileira e amplia significativamente sua influência sobre as políticas públicas. A força destes segmentos junto ao Estado deteve a redução mais expressiva das taxas de juros, mesmo a eliminação dos déficits em conta corrente - através de um ajuste recessivo, quedas salariais e forte desvalorização monetária apresentados inicialmente no governo FHC como uma das razões de seus patamares elevados.

Entretanto, esta conversão deste segmento estratificado de trabalhadores, através da alta burocracia sindical que gerencia os fundos de pensão, fazse em detrimento da situação social do conjunto da classe trabalhadora - apesar das políticas compensatórias praticadas - e das perspectivas de desenvolvimento do país e de sua projeção regional. A contradição entre as políticas praticadas por esta fração de classe e o conjunto da classe trabalhadora mostra 
a complexidade dos conflitos sociais que se desenvolvem no país e a necessidade de mobilizar-se o debate e a opinião pública para superar estas práticas corporativistas, antes que elas propiciem a volta da hegemonia dos velhos grupos burgueses sobre o Estado - até aqui profundamente desgastados -, renovados por um programa de corte mais desenvolvimentista.

\section{O governo Lula: políticas públicas e resultados}

A prioridade do governo Lula foi a de conter os desequilíbrios macroeconômicos gerados durante o governo FHC, notadamente, a dívida pública e os déficits em conta corrente, e os desequilíbrios sociais mais intensos através de políticas sociais para minorar a extrema pobreza. Para isso deu continuidade ou aprofundou políticas impulsionadas ao final do governo FHC: contenção dos gastos públicos e ampliação do superávit primário, estabelecimento do câmbio flutuante e implementação de políticas sociais ${ }^{9}$ para uma população ameaçada com a queda dos rendimentos, o desemprego crescente e a recessão econômica. Além disso, manteve o manejo das taxas de juros, significativamente apreciadas, como o principal instrumento de controle da inflação. Por outro lado, sustou políticas como as de privatização, impulsionando em seu lugar as licitações através das parcerias público-privadas, ampliando o papel do Banco Nacional de Desenvolvimento Econômico e Social (BNDES) no fomento da atividade industrial, o que serviu de contrapeso às políticas de altos juros.

É possível sintetizar os principais impactos e resultados das políticas públicas macroeconômicas estabelecidas pelo governo Lula através das asserções a seguir arroladas.

a) O crescimento econômico e seu padrão: o crescimento econômico está fortemente comprometido pelos altos juros praticados pelo Banco Central. Em 2003 , elevou-se a SELIC ${ }^{10}$ a $26,5 \%$ para produzirse uma forte recessão e restrição da demanda interna com o objetivo de realizar um ajuste macroeconômico no país. Buscou-se inverter os déficits comerciais e em conta corrente para a geração de significativos saldos capazes de financiar os egressos de capitais de estrangeiros que o país vinha sofrendo desde 1999, dadas as restrições impostas pelo governo de George W. Bush (2001) à expansão do financiamento internacional pelo FMI. Entretanto, o câmbio flutuante, a ampliação do papel creditício do BNDES - com o aumento das dotações e redução da taxa de juros de longo prazo - e a recuperação da economia mundial permitiram certa retomada do crescimento econômico em 2004, limitado em 2005. Esta retomada apresentou um padrão de expansão orientado para as exportações e ao setor de bens de consumo duráveis ${ }^{11}$, estimulando, ainda que em menor medida, ao setor de bens de capital ${ }^{12}$. Ela ao menos deteve a desindustrialização impulsionada, desde os anos 1980 e em particular no governo $\mathrm{FHC}^{13}$. Mas a sustentabilidade do crescimento requer, no entanto, uma queda significativa das taxas de juros ${ }^{14}$. Os saldos comerciais tendem a desvalorizar o dólar e a diminuir a rentabilidade das exportações ${ }^{15}$, limitando a dinâmica do crescimento e o investimento estrangeiro direto. Para estimulá-los torna-se crucial impulsionar a demanda interna e desvalorizar o câmbio, para o que pode contribuir decisivamente a flexibilização da política monetária e a expansão do crédito. Isto permitiria a convergência do crescimento em torno à demanda interna e às exportações, dando suporte a entrada de dólares.

b) O desenvolvimento tecnológico: a recuperação do setor de bens de capital através do câmbio flutuante e apoio do BNDES é ainda extremamente insuficiente. No governo FHC a desindustrialização afeta, sobretudo, a este segmento. Segundo os indicadores da CEPAL podemos observar que: em 1994, a produção de bens de capital equivalia a um índice de 122 para cair a 97,9, em 1999, e subir a 125, em 2002 (CEPAL, 2005). Essa queda se associa a uma brutal elevação de suas importações, que se ampliam à taxa anual de $37 \%$ entre 1994-97 e à brutal elevação das taxas de juros em 1998. A adoção do câmbio flutuante e a queda dos juros permitiram uma certa recuperação que se expande no governo Lula. Entretanto, permanece um forte déficit na balança comercial no segmento de alta complexidade tecnológica, que inclui os setores de eletrônicos, farmacêutico e perfumaria, de químicos diversos, refino de petróleo e petroquímicos, e o da indústria plástica. A recuperação e a modernização da produção de bens de capital exigem a elevação da taxas de investimento e o desenvolvimento da articulação entre as ciências básica e aplicada, a universidade e a empresa. Isto requer a liberação da destinação dos superávits primários e saldos comerciais - que juntos montam em aproximadamente $9-10 \%$ do PIB - ao pagamento de 
juros para que se orientem a um amplo programa de desenvolvimento nacional e regional ${ }^{16}$. A recuperação do setor de bens de capital é crucial para a elevação da intensidade tecnológica de nossas exportações, pois, em 2005, 70\% delas foram classificadas como de intensidade baixa e média-baixa ou não-industrializadas (FUNCEX, 2006).

c) As políticas sociais: o alcance das políticas sociais do governo Lula é profundamente limitado pelas restrições postas ao desenvolvimento econômico. Indicadores do IBGE apontam entre 1999-2003 uma elevação da população que ganha até dois salários mínimos ou não é remunerada, que passa de $62,4 \%$ a 67,3\%. O IPEA aponta também a elevação da taxa de pobreza, entre $2002-2003$, de $34 \%$ para $39 \%$, com sua queda posterior para 33\% em 2004. Para este descenso muito contribuíram os programas sociais do governo, pois a renda real média das pessoas, mesmo hoje em 2006, com o crescimento econômico moderado gerado a partir de 2004, permanece 4,3\% inferior às de $2002^{17}$. Trata-se, portanto, de um resultado bastante modesto, baseado na focalização de políticas sociais que prioriza por critérios conservadores - meio salário mínimo per capita - a população abaixo da linha de pobreza, excluindo um amplo contingente de pessoas com carência de necessidades básicas e que de fato empobreceu entre 2002-2006 (IBGE, 2006). A contradição entre os resultados e as metas esvaziou a retórica do Fome Zero em favor do Bolsa Família, um de seus programas, que ganhou maior destaque, indicando a prioridade que assumiu a focalização sobre a proposta inicial, mais ampla e ambiciosa de combate à pobreza.

d) O setor energético: a limitação das tarifas públicas, posterior à privatização do setor elétrico, e a imposição das metas de superávit primário, através do acordo do governo FHC com o FMI, foram decisivas para a crise da matriz energética, baseada na hidroeletricidade. Sem interesse na geração de energia, que requer altos investimentos, o setor privado concentrou-se na transmissão de energia, ao tempo em que os constrangimentos financeiros aos investimentos estatais na área limitaram a modernização das instalações e a ampliação da capacidade, levando ao uso das reservas aqüíferas das represas para a geração de energia adicional. A estiagem de 2001 trouxe o colapso ao sistema risco para o qual já alertavam os técnicos - pela incapacidade de dispor das reservas que haviam sido comprometidas nos períodos de normalidade pluviométrica. Para superar a escassez de energia o governo FHC impulsionou a substituição da matriz hidroelétrica pela termoelétrica, baseando-se para isso na importação do gás boliviano. Este deveria alimentar, sobretudo, o consumo de energia da indústria paulista. Entretanto, havia que se conter uma fonte de incertezas para esta substituição: a eleva- ção dos preços do gás, em função das oscilações do mercado de hidrocarburos, o que poderia afetar a lucratividade da indústria paulista. Para isso se estabeleceu um preço máximo a ser pago pelas termoelétricas brasileiras ao combustível importado e ofertado pela Petrobrás através do Programa Prioritário de Termoeletricidade (PPT): 2,581 MMBTU, corrigido anualmente pela inflação norte-americana, mas que está sem reajuste desde janeiro de $2003^{18}$. As pressões pelo reajuste de preços do gás importado pela Petrobrás, a nacionalização das reservas e o aumento dos tributos na Bolívia, com a eleição de Evo Morales (2006), colocaram em questão a sustentabilidade deste modelo. Diante disso, o Brasil pode seguir dois caminhos: de um lado, retroagir para a exploração de fontes nacionais de gás, ou de outro aprofundar a integração, redefinindo os seus termos de uma integração baseada na assimetria de poder estatal e competição para a parceria. Para ensejar a segunda alternativa, poderia se buscar o apoio interno no empresariado para elevação dos preços do gás, reduzindo-se, como contrapartida, o imposto financeiro das altas taxas de juros.

e) A política externa: a política externa do governo Lula, embora se paute por uma agenda muito similar a de Fernando Henrique Cardoso (pleito à vaga permanente no Conselho de Segurança da ONU, ênfase na integração regional, nas relações Sul-Sul e com a Ásia e África), caracteriza-se por um maior ativismo na condução da mesma (criação do G-20, do grupo de amigos da Venezuela, presença no Fórum Social Mundial, contenção da ALCA, aproximação com os BRICS). Entretanto, o alcance deste ativismo é fortemente limitado pelas políticas internas. O peso dos juros na economia brasileira absorve os superávits fiscais e a capacidade de investimento do Estado, restringindo a projeção brasileira na América do Sul. Impulsioná-la requer investimentos, seja para integrar mercados e amparar o comercialismo, ainda predominante no enfoque de nossa política externa ou, numa perspectiva mais ampla, com muito mais intensidade, para fundar uma integração eminentemente política, baseada na cooperação e na parceria, capaz de ultrapassar o assédio dos TLC's estadunidenses e criar um grande consenso na região em torno a um padrão de desenvolvimento socialmente e ecologicamente sustentável.

\section{Cenários e a política brasileira}

A partir deste contexto político, podemos desenhar três cenários possíveis para a economia brasileira nos próximos cinco anos.

No primeiro, mantém-se a política monetária e a política cambial. Neste caso, o crescimento econô- 
mico será muito limitado. A apreciação do câmbio pelo ingresso de dólares através dos superávits comerciais e do investimento direto tende a reduzir a rentabilidade das exportações, apesar das tendências de apreciação dos preços das commodities nos próximos cinco ou seis - se tomarmos em consideração a presença da fase prosperidade de Kondratiev expansivo, iniciada em 2003, e que deve durar aproximadamente até 2010. A prorrogação do crescimento econômico dependerá de uma forte contenção dos custos do trabalho que se apreciarão em níveis internacionais com a valorização do câmbio. Isto levará, como ocorreu durante o Plano Real, no governo FHC, à drástica queda dos rendimentos do trabalho na composição do PIB $^{19}$ e desafiará qualquer iniciativa de inclusão social baseada em políticas compensatórias. A valorização do real tende a transformar os superávits em déficits e a necessidade de sustentar o equilíbrio no balanço de pagamentos colocará na ordem do dia a privatização e a ampla concessão de serviços públicos para estimular a entrada de dólares, já que o setor exportador não terá muita capacidade de absorvê-los; os altos estoques da dívida pública dificultam a sua dinamização nos moldes anteriores; e a demanda interna não será fonte de dinamismo sustentável, apesar de estimulada inicialmente pela queda de preços que a competição estrangeira trouxer. Avançará a desindustrialização afetando, sobretudo, o segmento de bens de capital. A política externa brasileira será desafiada pelo crescente descompasso entre sua ênfase retórica ativista de integração regional e cooperação Sul-Sul e, de outro, sua incapacidade de alavancar os investimentos para realizála e liderar, na América do Sul, um processo de integração que seja uma alternativa efetiva a ALCA ou aos TLC's.

No segundo cenário, flexibilizam-se as taxas de juros, renegocia-se a dívida interna e se estabelece a prioridade dos investimentos produtivos sobre os financeiros, acompanhando-se as tendências da economia mundial. As taxas de crescimento se aceleram, as exportações mantêm altos níveis de rentabilidade e ao mesmo tempo estimula-se a demanda interna. A retomada em certos níveis da capacidade de investimento do Estado permite o estabelecimento de uma política de inclusão social moderada. Eleva-se a absorção de capitais estrangeiros e ao mesmo tempo a capacidade estratégica de direcioná-los. Rearticula-se o segmento de bens de capital e retomam-se os gastos estatais em ciência básica. A política externa brasileira passa a contar com maior capacidade de atuação e intervenção. Entretanto, mantém-se a dependência tecnológica e os esforços para a montagem de um sistema avançado de ciência e tecnologia ou para a qualificação da força de trabalho não vão muito longe, restringindo o alcance da inclusão social, a ofensiva internacional do país e a recomposição de suas elites dirigentes.

No terceiro cenário, combina-se uma política monetária expansionista com a criação de um importante sistema de ciência e tecnologia nacional e um projeto de inclusão social acelerada, onde se combinam a redistribuição da propriedade e da renda. Isto implica a recomposição interna das elites dirigentes, ampliando-se o espaço para a atuação dos movimentos sociais e de vastos segmentos das classes trabalhadoras. Desenvolvem-se os investimentos em educação, ciência e tecnologia, saúde, habitação, infra-estrutura básica, reforma agrária e emprego impulsionando-se a demanda interna e rompendo-se com a superexploração ${ }^{20}$. Articulam-se profundamente os laços entre indústria e universidade. Eleva-se fortemente a taxa de investimento a partir da poupança pública e garante-se uma longa trajetória de sustentabilidade do crescimento, mediante a sinergia entre a redução das desigualdades internas e o desenvolvimento tecnológico. A elevação da taxa de investimento exige uma ampla renegociação das dívidas interna e externa. Possíveis impactos internacionais negativos deste processo tendem a ser transitórios e mais que compensados pelo dinamismo interno do crescimento. Seu êxito econômico, em um ambiente mundial de alta competitividade, deverá atrair o capital estrangeiro, que seria direcionado para áreas estratégicas, em geral voltadas à exportação e complementares ao esforço tecnológico e científico nacional. Os superávits comerciais são estimulados por uma política cambial dirigida pelo Estado para garantir a competitividade das exportações nacionais. A política externa assume um formato cooperativo para projetar a liderança brasileira na América do Sul em nome de um processo de desenvolvimento regional que estimula a endogeneização dos fundamentos do progresso técnico e a eqüidade. Ela tende a se desdobrar num amplo processo de criatividade institucional, amparado pela renovação das elites dirigentes locais. Aprofundar-se-ia a integração energética sul-americana e a nacionalização das riquezas minerais e bióticas, buscando-se ampliar o domínio sobre fontes de energia sustentáveis, com forte destaque para a biomassa.

Em razão da composição de forças políticas e sociais que se projetam no país vemos como mais prováveis a construção do segundo cenário ou a permanência do primeiro, ou, ainda, de formas intermediárias entre eles. Ao nosso ver, a manutenção da hegemonia do Partido dos Trabalhadores na política brasileira depende fortemente de uma transição contundente ao menos, para o segundo cenário, enquanto que a permanência no primeiro paradigma de política econômica abriria amplos espaços para uma nova ofensiva da direita em busca do controle do Estado. 


\section{Referências}

ANAPAR - Associação Nacional dos Participantes de Fundos de Pensão Boletim Eletrônico n. 136, ano IV, 2004. Disponível em <www.anapar.com.br>. Acesso em: jun. 2006.

BANCO CENTRAL DO BRASIL. Publicações. Disponível em www.bcb.gov.br. Acesso em: out. 2006.

CEPAL. Anuario Estadístico de América Latina Y el Caribe 2004. Santiago, Chile; United Nations, 2005.

U. S. GOVERNMENT. Council of Foreign Affairs. Economic Report of the President. Washington, 2001-2006.

FUNCEX-Fundação Centro de Estudos do Comércio Exterior. Disponível em <www.funcex.com.br $>$. Acesso em: jun. 2006.

IBGE - Instituto Brasileiro de Geografia e Estatística. Disponível em <www.ibge.gov.br>. Acesso em: jun. 2006.

IPEA - Instituto de Pesquisa Econômica Aplicada. Estudos e pesquisas. Disponível em <www.ipea.gov.br $>$. Acesso em: jun. 2006.

PORCHMANN, M. et al. Atlas da Exclusão Social. Agenda não liberal da inclusão social no Brasil. São Paulo: Cortez, 2006. V.5.

MADDISON, A. The World Economy: a Millennial Perspective. Paris: OECD, 2001

UNCTAD - United Nations Conference on Trade and Development. World investment report, 2001-2005. United Nations, New York and Geneve, 2005.

\section{Notas}

1 Cumpre observar que a crise se inicia no segundo mandato de FHC, quando o crescimento econômico per capita anual caipara $0,6 \%$.

2 Entre 1970-81, o Brasil recebeu 23,7\% dos investimentos estrangeiros mundiais, entre 1982-93, esta parcela despenca para $9 \%(\mathrm{UNCTAD}, 2005)$.

3 Na China, excluindo-se Hong Kong, os indicadores de investimento direto indicam o forte deslocamento dos fluxos mundiais de capital para este país. Assim, se tomarmos em consideração os estoques de investimento direto e as entradas de capitais estrangeiros, podemos observar que: os estoques de investimento direto saltam de US\$ 1,074 bilhões em 1980, para US\$20,6 bilhões em 1990 e US\$245,6 bilhões em 2004. Por outro lado, os fluxos de entrada de capitais saltam de US\$ 57 milhões em 1980, para US\$3,4 bilhões em 1990 e US\$ 60,6 bilhões em 2004 (UNCTAD, 2005).

4 Entre 1970-79 a participação dos Estados Unidos nos fluxos de investimentos estrangeiros mundiais alcançava 45\%, entre 1980-93, baixou para $21,9 \%$ e entre $1994-04$, alcança 20,8\%(UNCTAD, 2005).

5 Se observarmos as séries de longo prazo de estoques de investimento direto estrangeiros internalizados, podemos destacaro aumento relativo da participação daAmérica Central e do México em relaçãoàAmérica do Sul e ao Brasil, o que se dá, principalmente, a partir de 1998, quando os ultrapassa: assim em 1980, aAmérica do Sul possuía um estoque de US\$ 29 bilhões e México e América Central US\$ 10,8 bilhões; em 1998, a América do Sul mantinha folgada liderança com um estoque deUS\$239,8 bilhões, ao passo que México eAmérica Central detinhamUS\$149 bilhões; em2004, MéxicoeAmérica Central já detinhamUS\$369 bilhões, enquanto que aAmérica do Sul alcançava apenas US $\$ 360,8$ bilhões. Se tomarmos em consideração Brasil e México, isoladamente, podemos observar os seguintes resultados: em 1994, o Brasil detinha um estoque de investimentos estrangeiros que alcançava US\$ 56,4 bilhões e o do MéxicoUS\$33,1 bilhões; em 1998, oBrasil mantinha a dianteira com US $\$ 88,7$ bilhões ao passo que o México atingia US\$ 63,8 bilhões; já em 2004 o México tinha larga vantagem com US\$182,5 bilhões enquanto que o Brasil alcançava apenas US\$151 bilhões(UNCTAD, 2005).

6 O estoque estadunidense de investimento estrangeiro no setor financeiro eleva-se de U\$ 200 bilhões para U\$ 413 bilhões entre 1994-98, para reduzir-seaU\$239 bilhões em 1999, esubir posteriormente, sem recuperar o nível anterior, em 2003. O Brasil, que lidera até 1998, na América Latina, os estoques de capital estrangeiro estadunidense, é ultrapassado largamente pelo México e vê sua participação relativa e absoluta cair. O México que em 1990 tinha estoques estadunidenses de U\$ 10 bilhões frente aos 14,3 bilhões do Brasil, salta para U\$ 26,6 bilhões enquanto o Brasil alcança U\$ 37 bilhões em 1998. A partir daí o quadro se inverte; em 2003, o Brasil detém estoques de apenas U\$29,9 bilhões, enquanto que o México aumenta seumontantepara U\$ 61,5 bilhões(UNCTAD, 2005).

7 A dívida externa do setor público ampliou-se no governo de FernandoHenrique Cardoso de 5,6\%, em 1995 para 14,5\%, em 2002(CEPAL, 2005). Acarga tributária, por sua vez, ampliou-se de $25,3 \%$ a $34,8 \%$ do PIB. Por sua vez arrecadou-se cerca de US\$ 80 bilhões com privatizações entre 1994-2002.

8 Os capitais estrangeiros que investem inicialmente na expansão da dívida pública federal, abandonam largamente este investimento a partir de 1998-9, em função do alto risco quanto a liquidezque apresentam. Em 2004, segundo Boletim da ANAPAR, os fundos de pensão concentravam $18 \%$ da dívida Pública, o que correspondia, por sua vez, a $67 \%$ dos seus investimentos (ANAPAR, 2006). Em maio de 2006, os bancos comerciais, de investimento e corretoras nacionais 
concentravam $26,6 \%$ dos investimentos na dívida pública, enquanto que os similares estrangeiros detinham apenas 1,2\% destes (BANCOCENTRALDOBRASIL, 2006).

9 OPrograma FomeZero gerencia diversas iniciativas dirigidas às populações de extrema pobreza: o principal é o Bolsa Família, que unificou programas criados ao final da gestão de FHC (Bolsa Escola, Bolsa Alimentação, Cartão Alimentação e Auxílio-Gás) ampliando suas dotações.

10 SELICéasigladeSistemaEspecial deLiquidaçãoeCustódia.É um sistema computadorizado do Banco Central, ao qual apenas as instituições financeiras credenciadas têm acesso. Funciona mais ou menos como a compensação de um banco, só que no mercadode títulos públicos: transfere os papéis parao comprador, aomesmotempoemquecredita ovalor da vendapara ovendedor.

11 Entre 2003-2005, as exportações representaram 96\% do crescimento ao passo que a demanda das famílias, apenas $38 \%$. Como diversos fatores intervêm positiva ou negativamente no crescimento, a soma de alguns de seus componentes pode ultrapassar $100 \%$.

12 O segmento de bens de capital sofreu forte sucateamento durante o governo FHC.

13 Em 1980, a indústria de transformação detinha 33,4\% do PIB. Entre 1993 e 2002 ela diminui sua parcela no PIB de 29\% para $23 \%$. No governo Lula esta se eleva para $24,2 \%$ em 2005 . Por outro lado, a agropecuária aumentou seu peso no PIB de $7,5 \%$ para $8,8 \%$ neste mesmo período. Este crescimento se manteve até 2004 , quando atinge $10 \%$ do PIB recuando em 2005 para 8,4\%(IPEA, 2006).

14 O seu lento descenso até os atuais $15,25 \%$ é ainda muito insuficiente, dado que seu valor real permanece muito acima do crescimento econômico, elevando o peso da especulação na economia brasileira.

15 Os estudos da Fundação Centro de Estudos do Comércio Exterior (FUNCEX) para 2006 indicam uma redução da rentabilidade das exportações de aproximadamente $15 \%$, em relação a dezembro 2003 (FUNCEX, 2006). A intensidade desta queda tem sido contida pela elevação do preço das commodities associada ao crescimento da economia mundial.

16 As taxas de investimento estão entre $19 \%$ e $20 \%$ do PIB, muito abaixo, dos $24 \%$ do PIB alcançados entre 1970-79. A liberação de 70 a $80 \%$ dos excedentes obtidos com o saldo comercial e o superávit primário permitira alavancar um novo padrão de desenvolvimento.

17 Comparamos aqui o período janeiro-março.

18 Já em 2001 os preços internacionais do gás experimentaram forte alta, ultrapassando os 4 MMBTU, e iniciando sua tendência ascendente.
19 Entre 1994-2002, a queda da participação da remuneração do trabalho no PIB é muito expressiva. Em 1994, a remuneração do trabalho alcançava $46 \%$ do PIB e, em 2002, apenas $36 \%$ deste(IBGE).

20 Segundo Márcio Porchmann, e outros pesquisadores da UNICAMP, para reverter de forma acelerada - 15 anos - a exclusão social e obter uma inserção avançada no sistema mundial, o Brasil deveria investir nestas prioridades anualmente cerca de $27,4 \%$ do seu PIB. Para reverter de forma moderada e alcançar uma inserção intermediária deveria investir 14,5\% do seu PIB. Índices inferiores e distanciados deste patamar de investimento, colocariam o país sob o risco de ter seu níveis de exclusão social aumentados (PORCHMANN etal., 2006).

\section{Carlos Eduardo Martins}

Doutor em Sociologia pela Universidade de São Paulo (USP)

Professor de Relações Internacionais da Univ. Estácio de Sá

Pesquisador na Cátedra e Rede Unesco em Economia Global e Desenvolvimento Sustentável, da Rede de Estudios de la Economia Mundial de BUAP, do Grupo de Trabalho sobre Estados Unidos da CLACSO e do Laboratório de Políticas Públicas da UERJ.

Universidade Estácio de Sá

Curso de Relações Internacionais

Campus Arcos da Lapa

Rua Riachuelo, 27 - Centro

Rio de Janeiro - RJ

CEP: 20230-010 